\title{
Editorial
}

\section{The Ketogenic Diet: An Onomastic Opportunity to be Helpful}

\author{
Sanjay Kalra ${ }^{1}$ Rahul Rosha ${ }^{2}$ Rajiv Singla ${ }^{3}$ \\ ${ }^{1}$ Department of Endocrinology, Bharti Hospital, Karnal, \\ Haryana, India \\ 2Department of Nutrition, Novique Healthcare, Pune, \\ Maharashtra, India \\ ${ }^{3}$ Department of Endocrinology, Kalpavriksh Superspeciality Clinic, \\ Dwarka, New Delhi, India
}

J Soc Health Diab 2018;6:61-62.

The ketogenic diet (KD) is an oft-discussed topic in metabolic medicine, with a fairly well-defined mechanism of action, proven metabolic efficacy and nonmetabolic benefits, and documented safety and tolerability. ${ }^{1}$ However, KD has not achieved its rightful place in modern diabetes therapy. KD continues to be given step motherly or Cinderella treatment by various professional bodies, which mention it either in passing $^{2}$ or not at all. ${ }^{3-6}$

\section{The Need for a Name}

One reason for this may be the association that ketosis, or presence of ketone bodies in circulation, has with disease and ill health. In fact, ketosis or ketonuria is usually considered a Cassandra situation by physicians. Cassandra, the princess of Troy, and daughter of Priam and Hecuba, was blessed with the power to predict the future. However, she was cursed as well: no one believed her predictions, she was ignored as a mad woman by her family, and she was violated for no fault of hers. Similarly, though KD has salutogenic or healthpromoting properties, its benefits are often ignored by the scientific community. ${ }^{7,8}$

\section{A Euthymic Synonym}

Ketosis, produced by a KD, is therapeutic in nature, and is distinct from the pathological ketonuria seen with diabetic ketoacidosis. Thus, the KD should actually convey a Euphrosynean connection, akin to the Greek grace or charity of healing. Unfortunately, for us modern readers, most of whom are not conversant with Euphrosyne, the supposedly pathogenetic features of ketosis seem to overwhelm its salutogenic aspects in current medical literature.

One way of resolving this challenge may be to rename the KD with a more euthymic synonym. Such a name, if chosen, should create a sense of confidence and good health in the minds of health care providers, patients, and the public. It should be easy to pronounce, easy to write, and amenable to brevity, perhaps as an acronym. The acronym, or phrase, should have an appropriate meaning, and should not be vulnerable to misuse or trolling.

\section{Therapeutic Names}

The phrase "ketogenic diet" relies on the mechanism of action of the dietary plan, but does not share the anticipated outcome of the therapy, such as weight loss, glucose control, or seizure reduction. A more appropriate name for it may be therapeutic high protein (THP) diet, therapeutic low carbohydrate diet (TLC), or therapeutic macronutrient plan (TMP). Yet another list of monikers includes metabolic modulatory meal plan (3M plan), therapeutic macronutrient ratio diet (TMRD), or salutogenic macronutrient ratio therapeutic (SMART) diet.

Focusing on the carbohydrate restriction of KD may be more acceptable than highlighting its ketogenicity, but still seems CRIMINAL (carbohydrate restriction in metabolic illness). CRAP (carbohydrate restriction approach) does not sound too appealing, either. TRICK (therapeutic restriction intake of carbohydrate, with ketogenesis) is a correct description of KD's mechanism. Unfortunately, this too, carries a negative connotation.

\section{Protein-Rich Nomenclature}

Names which focus on the high protein character of KD can also be considered. These names utilize the healthy perception of protein, rather than the morbid halo of ketosis, to convey the mechanism of action of the diet. Examples include PRIME (protein-rich intervention for metabolic and endocrine) and ENDOPRICE (endocrine diet of protein rich, infinitesimal carbohydrate energy source).
License terms

(ㅇ)(1) $\Theta \circledast$ 
Our favorite, is TPE (therapeutic protein enhanced) diet, which reminds the reader of another, well-established TPE, that is, therapeutic patient education. PREFER-C (proteinenhanced, fat-enhanced restricted carbohydrate) diet is an even more comprehensive description of $\mathrm{KD}$, which encourages its use. At the same time, as responsible health care providers, we must be aware that KD may not be the preferred choice for all individuals.

\section{The Goodness of Ketosis}

A slightly long name, "eumetabolic low glucose intervention with calorie maintenance (EULOGICAL maintenance) diet," serves two purposes. Apart from having a catchy acronym, which means good logic, it highlights the goodness of KD, and the relatively lesser importance of calorie restriction in this approach.

The simplest synonym for the KD, however, would be a HELPFUL (Health Enhancing, Low carbohydrate, Protein rich, Fat rich, Underutilized and Longevity) diet. The promoting features of KD all find mention in HELPFUL. Thus, HELPFUL conveys the mechanism of action, strategic planning, macronutrient composition, and anticipated outcomes of the intervention.

\section{Summary}

Helpful is that helpful does. Perhaps this brief communication will stimulate rebranding of the $\mathrm{KD}$, in more communication friendly words, so that it is able to help more and more people across the world.

\section{References}

1 Azar ST, Beydoun HM, Albadri MR. Benefits of ketogenic diet for management of type two diabetes: a review. J Obes Eat Disord. 2016;2(2). doi: 10.21767/2471-8203.100022

2 Bajaj S. RSSDI clinical practice recommendations for the management of type 2 diabetes mellitus 2017. Int J Diabetes Dev Ctries 2018;38(1, Suppl 1):1-115

3 Garber AJ, Abrahamson MJ, Barzilay JI, et al. Consensus statement by the American Association of Clinical Endocrinologists and American College of Endocrinology on the comprehensive type 2 diabetes management algorithm-2017 executive summary. Endocr Pract 2017;23(2):207-238

4 American Diabetes Association. Lifestyle management: standards of medical care in diabetes-2018. Diabetes Care 2018;41(Suppl 1):S38-S50

5 Evert AB, Boucher JL, Cypress M, et al. Nutrition therapy recommendations for the management of adults with diabetes. Diabetes Care 2014;37(Suppl 1):S120-S143

6 Sievenpiper JL, Chan CB, Dworatzek PD, Freeze C, Williams SL; Diabetes Canada Clinical Practice Guidelines Expert Committee. Nutrition therapy. Can J Diabetes 2018;42 (Suppl 1):S64-S79

7 Gupta L, Khandelwal D, Kalra S, Gupta P, Dutta D, Aggarwal S. Ketogenic diet in endocrine disorders: current perspectives. J Postgrad Med 2017;63(4):242-251

8 Cahill GF, Veech RL. Ketoacids? Good medicine? Trans Am Clin Climatol Assoc 2003;114:149-161, discussion 162-163 